\title{
Feasibility Study of 1 MW Standalone Hybrid Energy System: For Technical Institutes
}

\author{
Pragya Nema ${ }^{1}$, Sayan Dutta ${ }^{2}$ \\ ${ }^{1}$ Department of Electrical Engineering, Netaji Subhash Engineering College, Kolkata, India; ${ }^{2}$ Department of Electrical Engineering, \\ Netaji Subhash Engineering College, Kolkata, India. \\ Email: pra3sam@yahoo.co.in; sayandutta@gmx.com.
}

Received June 26 $6^{\text {th }}$, 2012; revised August $3^{\text {rd }}, 2012$; accepted August $14^{\text {th }}, 2012$

\begin{abstract}
Hybrid energy system (HES) is a combination of different renewable resources such as wind, solar, biomass, small/micro hydro, with fossil fuel powered diesel generator to provide electric power. This paper gives the design idea of optimized Hybrid Energy System for a certain technical college over a conventional diesel generator for a particular site in eastern India (Kolkata). For this hybrid system, the meteorological data of Solar Insolation, hourly wind speed, are taken for Kolkata-Eastern India (Longitude $88^{\circ} 22^{\prime}$ and Latitude $22^{\circ} 34^{\prime}$ ) and the pattern of load consumption of technical college are studied and suitably modelled for optimization of the hybrid energy system using HOMER software. This paper gives the detail hypothetical study for standalone hybrid energy system for technical institute in five stages: 1) Recent electric bill of the college for the year 2011;2) Studying the load demand for every month in a year; 3) Calculating the maximum, minimum and the average load demand; 4) Introducing the solar data in HOMER software; e) Designing the hybrid model. This system is more cost effective and environmental friendly over the conventional diesel generator. It should reduced approximate $70 \%-80 \%$ fuel cost over conventional diesel generator and also reduced the emission of $\mathrm{CO}_{2}$ and other harmful gasses in environments. The action plan is formed on the basis of cost effective modelling that is minimization of energy production cost in a long run.
\end{abstract}

Keywords: Hybrid Energy Systems; Technical Institute; PV-Solar; Optimization; DG Set

\section{Introduction}

Energy is vital for sustaining life on earth. It is needed to improve the quality of life by exploiting the natural resources. The careless exploitation of these resources ultimately affects the environment on which such systems thrive. The energy problem is thus synonymous to ecological and economical problems. The world energy demand has been increasing. The convention energy resources are exhaustible and limited in supply [1]. Therefore, there is an urgent need to conserve these resources and explore the wider use of alternative energy resources for example - solar, wind, hydro, biomass, etc. The hybrid energy system (HES) [2], has received much attention over the past decades. It is viable alternative solution [3] as compared to system which relies entirely on hydrocarbon fuel.

\section{Hybrid Energy Systems}

Hybrid energy systems combine two or more energy conversion devices, or two or more fuels for the same device, that when integrated, overcome limitation in either. A hybrid energy system [4] is a combination of two or more energy sources with fossil fuel powered genera- tor to provide electric power where the electricity [5] is either fed directly to [6] grid or to batteries for energy storage. The main reason of integrating renewable energy sources in a hybrid system is primarily to save fossil fuel (diesel). Therefore a diesel generator is mainly used as a backup. Hybrid system can be configured in three different ways: grid connected off-grid with distribution system and for direct supply. The first configuration is able to rely on grid if the hybrid system has problems. Similarly feeding the power to the grid, thereby, boosting the voltage and minimizing power cuts strengthens the grid. For off-grid configurations, the hybrid can either be connected to many load centres or can act as a source of supply for one or two loads, thus avoiding the need of a distribution system. An isolated off-grid system is usually used to charge batteries or supply power to small rural industry/households.

National Renewable Energy Laboratory (NREL)'s, Hybrid Optimization Model for Electric Renewable (HOMER version 2.19) has been used as the sizing and optimization software tool [7]. It contains a number of energy component models and evaluates suitable technology options based on cost and availability of resources. 
In this paper the system sizing [8-10] is carried out using HOMER-optimization and simulation software tool. The hybrid system for technical institutes are implemented in HOMER is shown in Figure 1 Analysis with HOMER requires information on resources, economic constraints, and control methods. It also requires inputs on component types, their numbers, costs, efficiency, longevity, etc. Sensitivity analysis could be done with variables having a range of values instead of a specific number.

\section{Renewable Energy Resources for Hybrid System}

The availability of renewable energy resources at a technical institute site is an important factor to develop the hybrid system. In many parts of the India wind and solar energy is abundantly available. These energy sources are intermittent and naturally available, due to these factor our first choice to power the technical institute will be renewable energy sources such as wind and solar. Weather data are important factor for pre-feasibility $[11,12]$ study of renewable hybrid energy system for any particular site. Here the Wind and Solar energy resources data are taken from NASA [11] for Kolkata-Eastern India (Longitude $88^{\circ} 22^{\prime}$ and Latitude $22^{\circ} 34^{\prime}$ ) and shown in Table 1. In Eastern India wind speed is an average and sun brightness is strong.

\subsection{Solar Energy Resource}

Hourly solar irradiation data for the year was collected from Environment Kolkata. Scaling was done on these

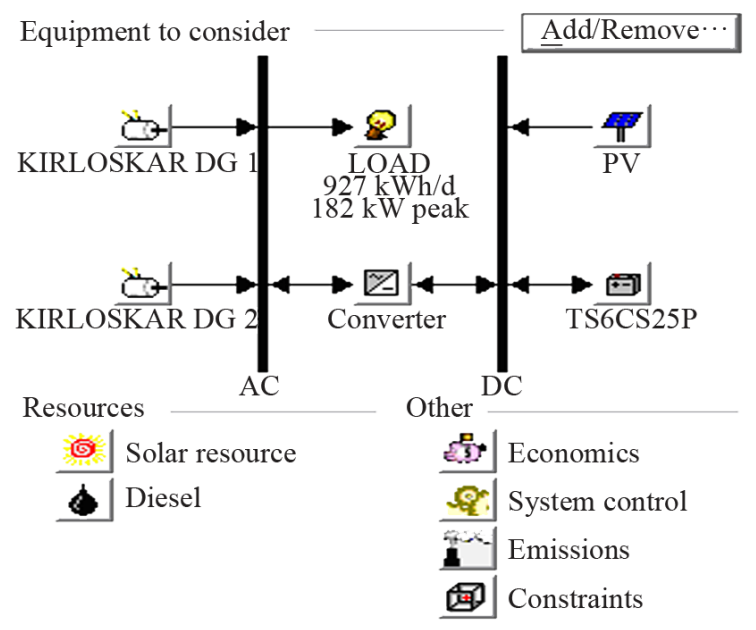

Figure 1. Hybrid system schematic diagram for technical institutes. data to consider the long-term average annual resource $\left(5.389 \mathrm{kWh} / \mathrm{m}^{2} / \mathrm{d}\right)$. The clearness index for the latitude and Average daily radiation in a year is shown in Figure 2. In summer solar power is higher than winter season. In rainy season clearness index and solar power availability is lower than summer and winter season.

\section{Load Pattern for Technical Institute}

In this present study consider the power requirements for technical institute are about $182 \mathrm{~kW}$ continuous. The load demand is approximate $927 \mathrm{Wh} / \mathrm{d}$ and $182 \mathrm{~kW}$ peak, that is shown in Figure 3.

\section{Hybrid Energy System Components}

The proposed hybrid system consists of the following:

\subsection{Photovoltaic System}

Solar PV modules are connected in series parallel. When the sunrays strike the Solar PV panels, it produces electricity. The Solar PV power at the site is higher than the wind power. A $1 \mathrm{~kW}$ solar panel installation and replacement costs are taken approximate as Rs. 42,876 and Rs. 30,000 respectively (Figure 4). The lifetime of the PV arrays are taken as 25 years.

\subsection{Diesel Generator Set (DG Set)}

We have used two $100 \mathrm{~kW}$ KIRLOSKAR DG set [12],

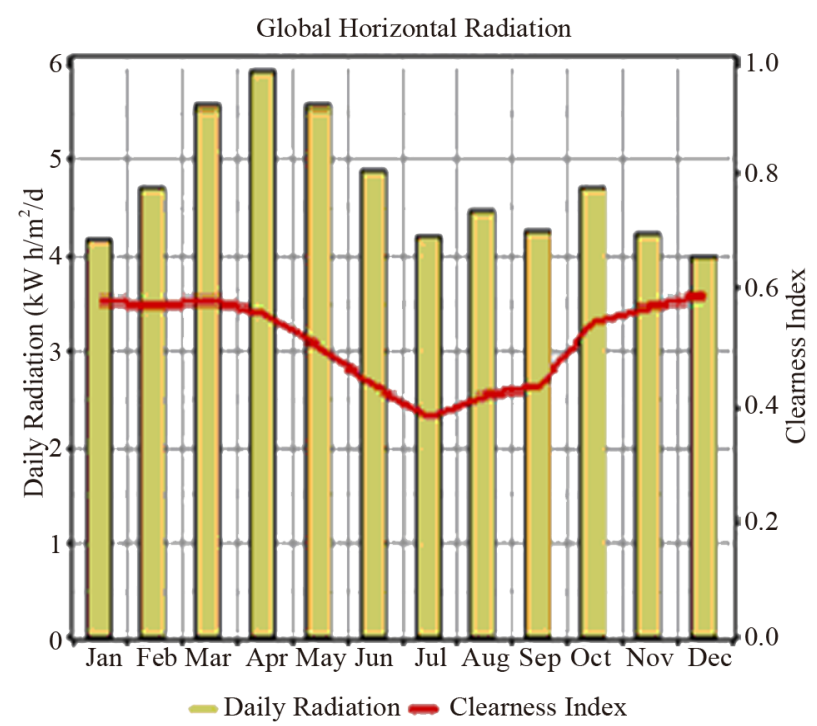

Figure 2. Global horizontal radiation and clearness index in a year.

Table 1. Monthly averaged insolation incident on a horizontal surface ( $\left.\mathrm{kWh} / \mathrm{m}^{2} / \mathrm{day}\right)$.

\begin{tabular}{cccccccccccccccc}
\hline $\begin{array}{c}\text { Lat 22 } \\
\text { Lon 88 }\end{array}$ & Jan & Feb & Mar & Apr & May & Jun & Jul & Aug & Sep & Oct & Nov & Dec & $\begin{array}{c}\text { Annual } \\
\text { Average }\end{array}$ \\
\hline $\begin{array}{c}\text { 22-year } \\
\text { Average }\end{array}$ & 4.26 & 4.93 & 5.66 & 6.11 & 5.82 & 4.51 & 4.11 & 3.99 & 3.94 & 4.36 & 4.24 & 4.13 & 4.67 & \\
\hline
\end{tabular}




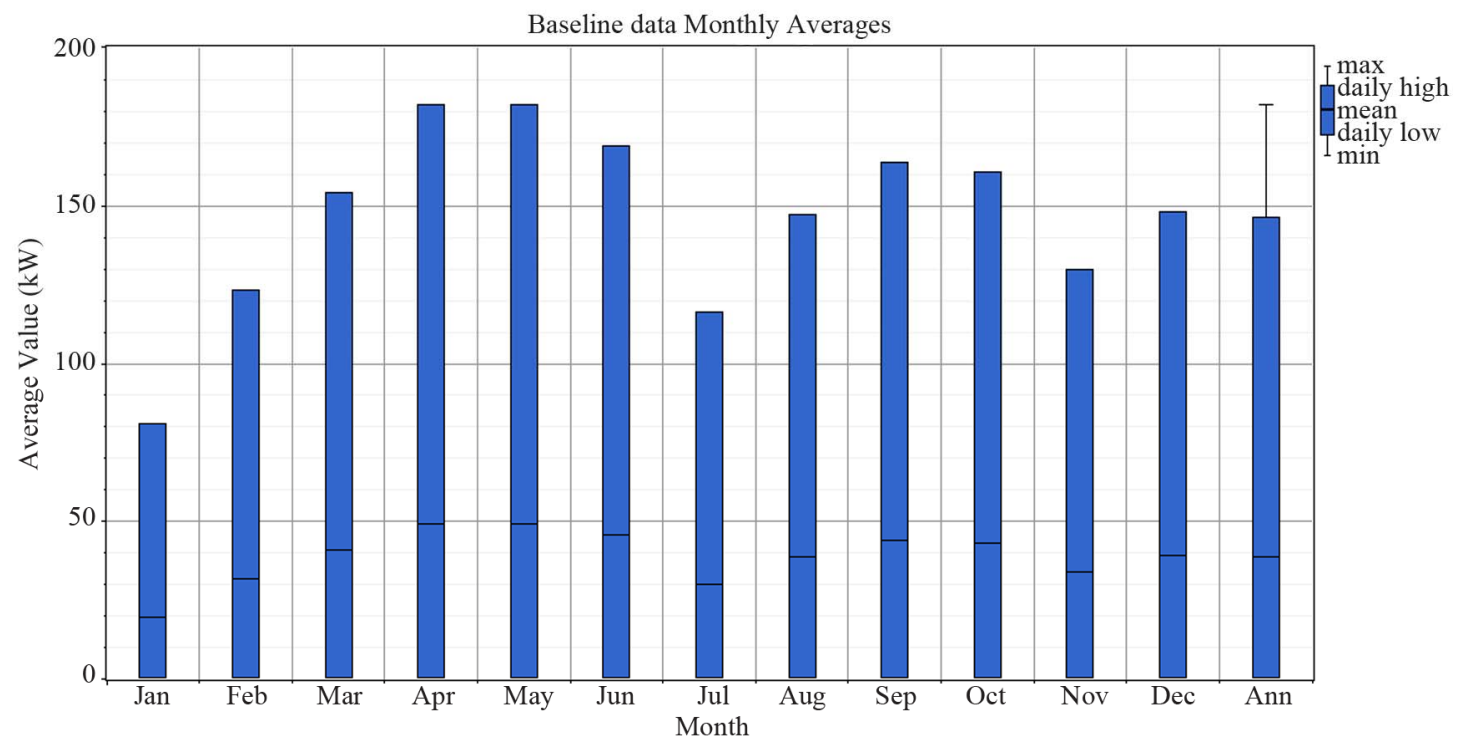

(a)

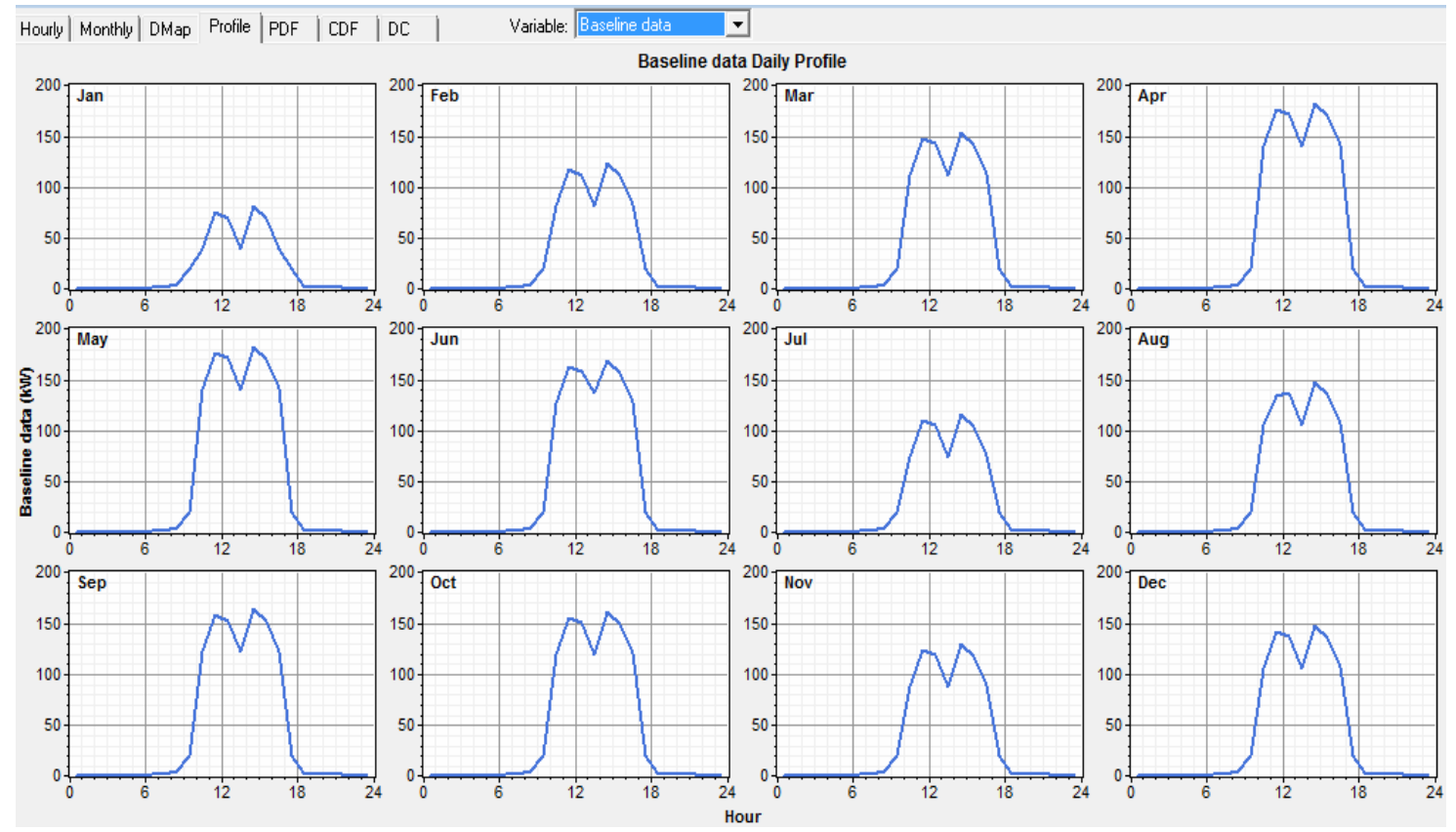

(b)

Figure 3. (a) \& (b) Load calculation from March 2010 to Jan 2011.

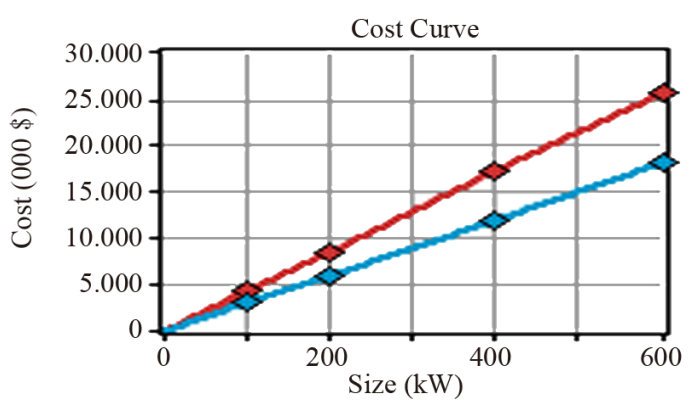

Capital $\longrightarrow$ Replacement

Figure 4. Cost curve of PV.

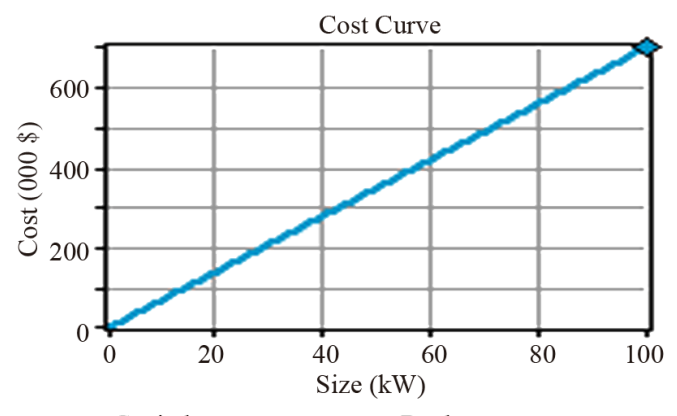

Capital Replacement

Figure 5. Cost curve of diesel generator 
which will be used as a backup. The output cost one DG set of Kirloskar is shown in Figure 5, considered to be Rs. 700,000 and the operating and the maintenance cost are found to be Rs. 230/hr. The Diesel price is used for sensitivity analysis and three discrete values (Rupees 46, 47, and 48 per litre) were introduced. At present, diesel price is around Rs. 46/lt and for a very remote location this could increase up to Rs. 480/lt.

\subsection{Battery}

A battery bank is used as a backup system and it also maintains constant voltage across the load. For battery we are using deep cycle battery manufactured by Rolls Battery Engineering $[11,13]$. The battery type recommended for using in solar PV system is deep cycle battery. Deep cycle battery is specifically designed for to be discharged to low energy level and rapid recharged or cycle charged and discharged day after day for years. The battery should be large enough to store sufficient energy to operate the appliances at night and cloudy days. The nominal voltage of one battery is $6 \mathrm{~V}$ with nominal capacity if $1156 \mathrm{Ah}$ and lifetime throughput $9645 \mathrm{kWh}$. Cost of one battery is Rs. 54,385 with a replacement cost of Rs. 34,000 (Figure 6).

\subsection{Converter}

A power electronic converter is needed to maintain flow

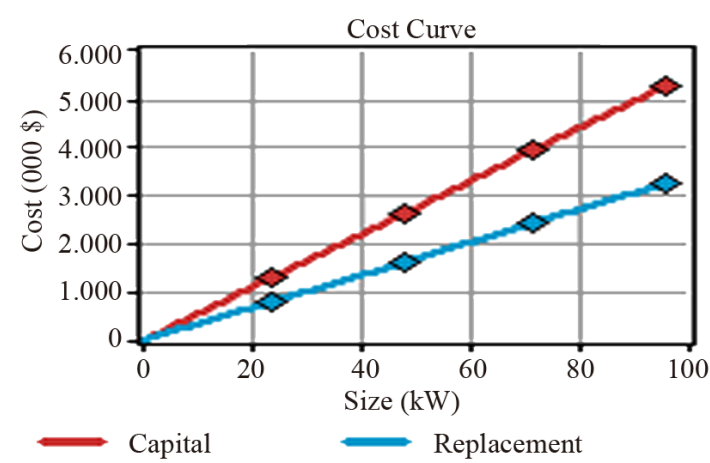

Figure 6. Cost curve of battery.

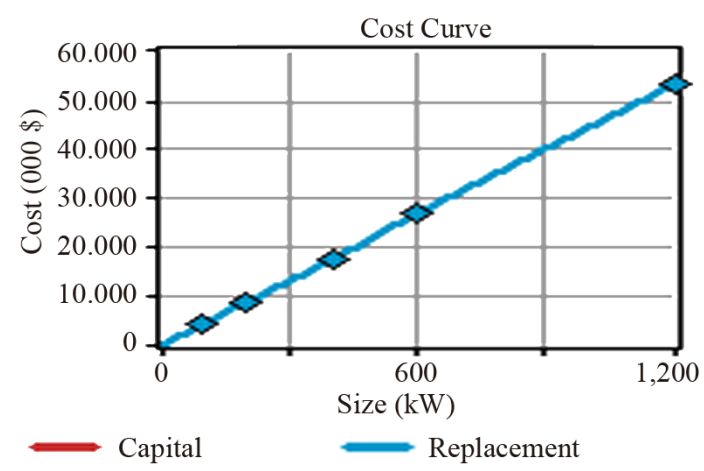

Figure 7. Cost curve of converter. of energy between the ac and dc components. For a $1 \mathrm{~kW}$ system the installation and replacement costs are taken as Rs. 44,504 and Rs. 3000, respectively. Cost analysis shown in Figure 7. Lifetime of a unit is considered to be 15 years with an efficiency of $90 \%$. Consider for this hybrid system $1200 \mathrm{~kW}$ converter.

\section{Results and Discussions}

The above proposed hybrid system supplies the power to the Technical Institute continuously throughout the year. For the analysis of this hybrid system we have considered four sensitivity variables (wind speed, solar irradiation, fuel cost and Battery cost). For each of the sensitivity values simulate all the systems in their respective. An hourly time series simulation for every possible system type and configuration is done for a 1-year period. An optimal system is defined as a solution for hybrid system configuration that is capable of meeting the load demand of the technical institute.

\subsection{Optimization Result}

From the optimization results the best optimal combination of energy system components are $600 \mathrm{~kW}$ PV-Array and two $100 \mathrm{~kW}$ diesel Generator. Total net present cost (NPC), Initial Capital cost and cost of energy (COE) for such a system is Rs. 50,971,348 Rs. 33,977,400 and Rs. $11.784 / \mathrm{kWh}$, respectively for one year. The detailed optimization results are shown in Figure 8.

The dollar symbol is taken as Indian rupees.

\subsection{Simulation Result}

The simulation result eliminates all infeasible combinations and ranks the feasible systems according to increasing net present cost. It also allows a number of parameters to be displayed against the sensitivity variables for identifying an optimal system type. The Monthly Average Electricity Production of Hybrid Energy System is shown in Figure 9. In this system the total production of electrical energy is fulfilled by PV array and the two DG sets. $95 \%$ is covered by PV, 4\% by Kirloskar DG 1 and the remaining $1 \%$ by Kirloskar DG 2 .

\section{Conclusions}

According to the load data of "Netaji Subhash Engineering College" the yearly tariff including the output and maintenance cost of the two DG set is around Rs. 2,977,002. On the hand the output and maintenance cost of in the new hybrid energy system is Rs. 1,329,381. The initial capital needed for this kind of hybrid energy system is the only disadvantage but only in the beginning. In the long run this hybrid energy system will be more profitable and as well as environment friendly solution. 


Sensitivity Results
Optimization Results

Figure 8. Optimization results of hybrid energy system.

\begin{tabular}{|c|c|c|c|c|c|c|c|c|c|c|}
\hline System Architecture: & \multicolumn{8}{|c|}{$\begin{array}{l}100 \text { kW KIRLOSKAR DG } 200 \text { kW' Inverter } \\
100 \text { kW KIRLOSKAR DG :200 kW Rectifier }\end{array}$} & \multicolumn{2}{|c|}{$\begin{array}{l}\text { Total NPC: } \$ 50,971,348 \\
\text { Levelized COE: } \$ 11.784 / \mathrm{kV} \\
\text { Operating Cost: } \$ 1,329,381\end{array}$} \\
\hline Cost Summary | Ca & Cash Flow & Electrical & PV & DG S & Battery & Converter | Emissior & $\mathrm{ns} \mid \mathrm{Hc}$ & ata | & & \\
\hline \multicolumn{2}{|c|}{ Production } & $\mathrm{kWh} / \mathrm{yr}$ & $\%$ & & Consumption & $\mathrm{kWh} / \mathrm{yr}$ & $\%$ & Quantity & $\mathrm{kWh} / \mathrm{yr}$ & $\%$ \\
\hline \multicolumn{2}{|l|}{ PV array } & 630,754 & 95 & & AC primary load & 338,365 & 100 & Excess electricity & 279,158 & 42.0 \\
\hline \multicolumn{2}{|c|}{ KIRLOSKAR DG 1} & 27,589 & 4 & & Total & 338,365 & 100 & Unmet electric load & 0.00163 & 0.0 \\
\hline \multicolumn{2}{|c|}{ KIRLOSKAR DG 2} & 5,595 & 1 & & & & & Capacity shortage & 0.00 & 0.0 \\
\hline \multirow[t]{2}{*}{ Total } & & 663,938 & 100 & & & & & Quantity & & \\
\hline & & & & & & & & Renewable fraction & & 0.950 \\
\hline
\end{tabular}

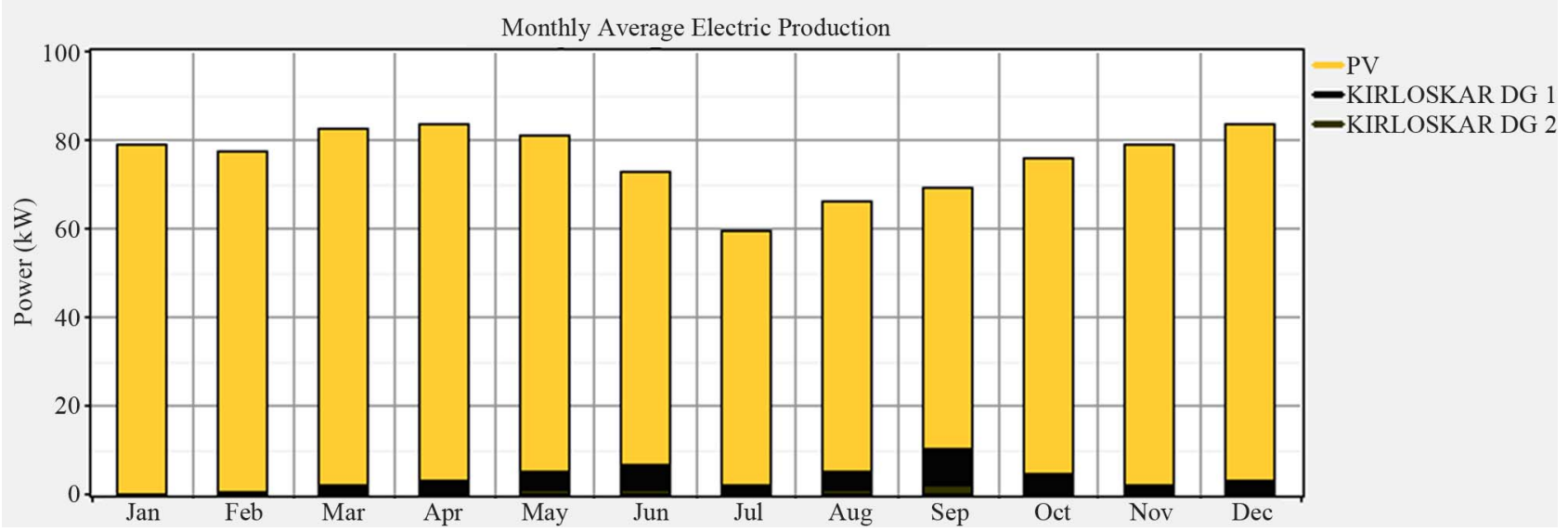

Figure 9. Annual electricity production by different hybrid system.

On the basis of what we have seen so far, we can conclude that this technology is the need of the future.

Solar-based-powered sites benefit the environment as well as the operator business case, whether they are located in highly populated or remote areas. Due to powering the base station by hybrid renewable energy system, it will reduce the carbon and other harmful gases emission is about $90 \%$ in environments. Due to powering the base station by hybrid renewable energy system, it will reduce the carbon and other harmful gases emission is about $90 \%$ in environments hence is non polluting and our future generation won't have to compensate on usage of natural resources. This kind of technology is a step to- wards sustainable development. Though it has high installation cost but in a long run it is highly profitable because it has a low operating and maintenance cost. It can be tailored to the needs of end use market. It serves to enhance the economic development and living standards of remote area. This can be upgraded to the need if required in the future. Hence this is a much needed step to avoid a situation of energy crisis in the near future.

\section{Acknowledgements}

The authors acknowledge gratefully the director of NETAJI SUBHASH ENGINNERING COLLEGE-KOLKATA for providing the load data used in this study. 


\section{REFERENCES}

[1] S. Ashok, "Optimized Model for Community-Based Hybrid Energy Systems,” Renewable Energy, Vol. 32, No. 7, 2007, pp. 1155-1164. doi:10.1016/j.renene.2006.04.008

[2] K. Katti and M. K. Khedkar, “Alternative Energy Facilities Based on Site Matching and Generation Unit Sizing for Remote Area Power Supply,” Renewable Energy, Vol. 32, No. 8, 2007, pp. 1346-1362. doi:10.1016/j.renene.2006.06.001

[3] M. J. Khan and M. T. Iqbal, "Pre-Feasibility Study of Stand-Alone Hybrid Energy Systems for Applications in Newfoundland," Renewable Energy, Vol. 30, No. 6, 2004, pp. 835-854. doi:10.1016/j.renene.2004.09.001

[4] A. N. Celik, "The System Performance of Autonomous Photovoltaic-Wind Hybrid Energy Systems Using Synthetically Generated Weather Data," Renewable Energy, Vol. 27, No. 1, 2002, pp. 107-121. doi:10.1016/S0960-1481(01)00168-9

[5] H. X. Yang, L. Lu and J. Burnett, "Weather Data and Probability Analysis of Hybrid Photovoltaic-Wind Power Generation Systems in Hong Kong,” Renewable Energy, Vol. 28, No. 11, 2003, pp. 1813-1824. doi:10.1016/S0960-1481(03)00015-6
[6] S. M. Shaahid and M. A. Elhadidy, “Opportunities for Utilization of Stand-Alone Hybrid (Photovoltaic + Diesel + Battery) Power Systems in Hot Climates,” Renewable Energy, Vol. 28, No. 11, 2003, pp. 1741-1753. doi:10.1016/S0960-1481(03)00013-2

[7] https://analysis.nrel.gov/homer/

[8] M. A. Elhadidy and S. M. Shaahid, "Role of Hybrid (Wind + Diesel) Power Systems in Meeting Commercial Loads,” Renewable Energy, Vol. 29, No. 12, 2004, pp. 109-118. doi:10.1016/S0960-1481(03)00067-3

[9] P. Nema, R. K. Nema and S. Rangnekar, "Integrated Design Approach for Stand Alone PV-Solar and Wind Hybrid Energy System: For Rural Electrifications,” International Conference on Advance Energy Systems (ICAER2007), IIT Bombay, 12-14 December 2007, pp. 354-359.

[10] P. Nema, R. K. Nema and S. Rangnekar, "Sizing and Methodology of PV-Solar/Wind Hybrid Energy Systems,” National Conference of Power Electronics \& Intelligent Control, Malaviya National Institute of Technology Jaipur (Rajasthan), 17-18 March 2007, pp. 291-294.

[11] http://eosweb.larc.nasa.gov/sse/

[12] http://www.kirloskar-electric.com/gens.shtml.

[13] www.rollsbattery.com 